\title{
CORRIGENDUM
}

\section{Low-echoic lesions underneath the skin in subjects with spinal-cord injury}

N Kanno, T Nakamura, M Yamanaka, K Kouda, T Nakamura and F Tajima

Spinal Cord (2009) 47, 505; doi:10.1038/sc.2009.21

Spinal Cord (2009) 47, 225-229; doi:10.1038/sc.2008.101; published online 5 August 2008

Since the publication of the above article, the authors have noticed that Table 4 is incorrect.

Table 4 Dimensions and depth of the low echoic lesions

\begin{tabular}{lccr}
\hline Abnormal & Ultrasound only $(\mathrm{n}=9)$ & Palpation and ultrasound $(\mathrm{n}=6)$ & P-value \\
\hline Longitudinal diameter $(\mathrm{cm})$ & $0.58 \pm 0.18$ & $0.81 \pm 0.26$ & 0.070 \\
Lateral diameter $(\mathrm{cm})$ & $2.20 \pm 0.49$ & $2.57 \pm 1.01$ & 0.399 \\
Depth $(\mathrm{cm})$ & $0.81 \pm 0.20$ & $0.31 \pm 0.23$ & 0.001 \\
\hline
\end{tabular}

The correct Table 4 is shown below.

The authors would like to apologize for this mistake.

Values are mean \pm s.d. 